\title{
Non-surgical care for locally advanced breast cancer: Radiologically assessed therapeutic outcome of a new enzyme-targeting radiosensitization treatment, Kochi Oxydol-Radiation Therapy for Unresectable Carcinomas, Type II (KORTUC II) with systemic chemotherapy
}

\author{
KANA MIYATAKE, KEI KUBOTA, YASUHIRO OGAWA, NORIHIKO HAMADA, \\ YORIKO MURATA and AKIHITO NISHIOKA \\ Department of Radiology, Kochi Medical School, Kochi University, Kohasu, Oko-cho, Nankoku, Kochi 783-8505, Japan
}

Received June 9, 2010; Accepted July 23, 2010

DOI: $10.3892 /$ or_00000968

\begin{abstract}
We have previously developed a new enzymetargeting radiosensitization treatment named Kochi OxydolRadiation Therapy for Unresectable Carcinomas, Type II (KORTUC II), which markedly enhances radiotherapeutic effects on various types of locally advanced malignant neoplasms. KORTUC II was approved by our local ethics committee for use against various types of malignant neoplasms. A maximum of $6 \mathrm{ml}$ of radiosensitizer was injected into tumor tissue under ultrasonographic guidance just before each administration of radiotherapy. Seventeen patients with locally advanced breast cancer were enrolled to receive KORTUC II with systemic chemotherapy without surgical care. Patients were eligible if they had declined surgical treatment. Median observation period was 13.4 months (range, 1-26 months). This therapy was well tolerated. Contrastenhanced magnetic resonance imaging revealed complete response in all primary breast tumors, and no patients displayed local recurrence during the follow-up period. Ultrasonography depicted tumor-like findings in 9 of 17 cases after therapy. The existence rate of posterior shadow artifacts behind the tumor was $2 / 17$ before therapy, increasing to $8 / 17$ after therapy. Intratumoral flow signals on color Doppler sonography were seen in 16/17 cases before therapy, but had disappeared from all cases after therapy. The increased rate of posterior shadow artifacts and absence of flow signals after therapy suggest that the tumor-like finding on ultra-
\end{abstract}

Correspondence to: Dr Kana Miyatake, Department of Radiology, Kochi Medical School, Kochi University, Kohasu, Oko-cho, Nankoku, Kochi 783-8505, Japan

E-mail: jm-kanakana@kochi-u.ac.jp

Key words: radiation therapy, radiosensitizer, breast cancer, ultrasonography, computed tomography, magnetic resonance imaging, positron emission computed tomography sonography represents scar tissue. Computed tomography revealed positive axillary nodes metastases in 16/17 and 2/17 cases before and after therapy, respectively. Nodal metastatic failure affected only 1 patient, who refused adjuvant systemic chemotherapy at the end of the observation period. Abnormal lymph node findings on computed tomography remained stable in the other patient. Excellent locoregional control based on accurate radiological evaluation implies that KORTUC II with chemotherapy has the potential to replace surgery in therapy for locally advanced breast cancer.

\section{Introduction}

Large tumors $(>5 \mathrm{~cm})$ and/or extensive regional lymph node involvement, which correspond to stage IIIA, IIIB and IIIC in the TNM stage classification, are widely called locally advanced breast cancer (LABC) (1). Induction chemotherapy is considered essential in the care of LABC (2-6). Surgery alone and radiotherapy alone following induction chemotherapy for LABC both result in similar survival rates $(5,6)$. Progress in radiotherapeutic methods may thus obviate surgical care as a therapeutic option for LABC. We have introduced a new enzyme-targeting radiosensitizer and have reported the efficacy of radiotherapy with this new radiosensitizer in vivo and in clinical trials (7-11). This radiosensitizer inactivates peroxidase/catalase in tumor tissue through the application of hydrogen peroxide, thus reoxygenizing the tumor tissue with the oxygen produced by the degradation of hydrogen peroxide $(10,11)$. We have named this new enzyme-targeting radiosensitizer treatment, which uses hydrogen peroxide and sodium hyaluronate, Kochi Oxydol-Radiation Therapy for Unresectable Carcinomas, Type II (KORTUC II) (11). In the current study, we introduced KORTUC II with systemic chemotherapy to achieve non-surgical control of LABC. We consider that accurate monitoring of therapeutic efficacy is prerequisite to achieving definitive advances in LABC care. The goal of the present study was to determine the therapeutic outcomes of our new approach as assessed by imaging modalities, including contrast-enhanced (CE) breast magnetic resonance imaging 


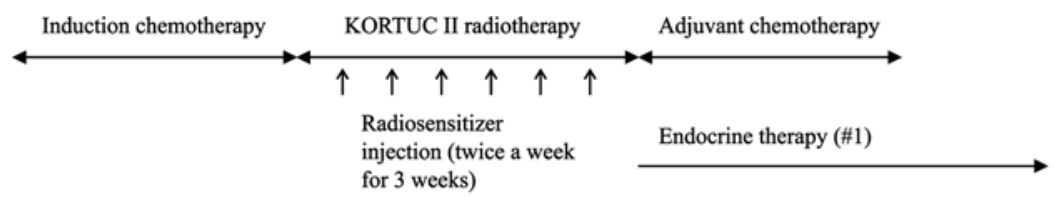

Follow up radiological test (\#2)

Figure 1. Protocol for care and follow-up examinations. \#1, endocrine therapy was planned to be continued for 5 years among eligible patients, if the tumor was hormone receptor-positive; \#2, assessment of therapeutic outcomes started after the completion of adjuvant chemotherapy.

(MRI), ultrasonography (US), chest computed tomography (CT) and $\left[{ }^{18} \mathrm{~F}\right]$-fluorodeoxyglucose positron emission CT (FDG-PET-CT).

\section{Materials and methods}

The present study describes KORTUC II radiosensitization therapy using a new radiosensitizer containing hydrogen peroxide and sodium hyaluronate combined with systemic therapy. This was used as an injection into LABC as approved by our local ethics committee. Since hydrogen peroxide is an irritant that may cause severe adverse effects, we developed a new hydrogen peroxide-containing radiosensitizer that is safe for direct injection into breast tumor, effectively conferring radiosensitivity while avoiding irritation of local tissue. All patients received induction chemotherapy followed by KORTUC II radiosensitization therapy and adjuvant chemotherapy (after radiotherapy) plus endocrine therapy, if the tumor showed positive results for hormone receptors (Fig. 1). CE breast MRI, US and chest CT were performed to assess baseline tumor and axillary lymph node status within 1 month before starting therapy. Responses of primary breast tumor to induction chemotherapy were assessed by CE breast MRI after completing induction chemotherapy, just prior to start of radiotherapy. Adjuvant chemotherapy regimens were determined based on the response to induction chemotherapy.

Preparation of the radiosensitizing agent. The radiosensitizing agent is composed of $0.83 \%$ sodium hyaluronate and $0.5 \%$ hydrogen peroxide. The agent is currently prepared by adding $0.5 \mathrm{ml}$ of $3 \%$ hydrogen peroxide solution (Oxydol; Ken-ei Pharmaceutical, Osaka, Japan) into a commercially available disposable syringe containing $2.5 \mathrm{ml}$ of $1.0 \%$ sodium hyaluronate, which is ordinarily used for intra-articular injection in chronic knee joint disorders. Hydrogen peroxide is added just before use, to avoid the degradation of sodium hyaluronate by the oxidative effects of hydrogen peroxide.

Patient selection and radiotherapy. Seventeen women with LABC (invasive ductal carcinoma) were enrolled to receive KORTUC II combined with systemic therapy between October 2006 and March 2009. Each patient was enrolled after providing written, fully informed consent. Patient data are summarized in Tables I and II. Patients were eligible if they had declined surgical treatment for the LABC. For these patients, radiotherapy with high-energy X-rays was delivered using an EXL-20TP linear accelerator equipped with a multileaf collimator (Mitsubishi Electric, Tokyo, Japan) at an
Table I. Profiles of all patients.

\begin{tabular}{rll}
\hline Case & Age (years) & \multicolumn{1}{c}{ TNM stage } \\
\hline 1 & 44 & T3N1M0, stage IIIA \\
2 & 60 & T2N3aM0, stage IIIC \\
3 & 49 & T3N1M0, stage IIIA \\
4 & 57 & T4bN3cM0, stage IIIC \\
5 & 65 & T4cN3bM0, stage IIIC \\
6 & 56 & T2N2M0, stage IIIA \\
7 & 67 & T1cN2M0, stage IIIA \\
8 & 57 & T4bN1M0, stage IIIB \\
9 & 53 & T2N2M0, stage IIIA \\
10 & 36 & T2N2M0, stage IIIA \\
11 & 59 & T2N2M0, stage IIIA \\
12 & 60 & T4bN0M0, stage IIIB \\
13 & 45 & T4cN1M0, stage IIIB \\
14 & 67 & T4aN1M0, stage IIIB \\
15 & 43 & T3N1M0, stage IIIA \\
16 & 47 & T2N2M0, stage IIIA \\
17 & 62 & T4aN1M0, stage IIIB \\
\hline
\end{tabular}

appropriate energy level (4 MV). Hypofraction radiotherapy was administered using a tangential field approach, with a total radiation dose of $49.5 \mathrm{~Gy}$ administered at $2.75 \mathrm{~Gy} /$ fraction. Radiotherapy was performed 5 times/week for each patient. After starting radiotherapy, intra-tumoral injection of the new radiosensitizer was performed under ultrasonographic guidance twice a week for 3 weeks, just prior to radiotherapy. A maximum of $6 \mathrm{ml}$ of the agent was injected.

Induction and adjuvant chemotherapy and trastuzumab. Systemic EC regimen was administered 4-6 times as induction chemotherapy (prior to radiotherapy), according to the tumor size. Adjuvant chemotherapy (after radiotherapy) was selected from 4 cycles of EC regimen (if induction EC had proven effective) or 4 cycles of taxane-based regimen [if induction EC had proven ineffective or the tumor showed human epidermal growth factor receptor type 2 (HER2) overexpression]. The dose provided with each administration of EC chemotherapy was $90 \mathrm{mg} / \mathrm{m}^{2}$ of epirubicin and $600 \mathrm{mg} / \mathrm{m}^{2}$ of cyclophosphamide injected every 3 weeks. Patients selected the preferred taxane (docetaxel or paclitaxel) depending on the 
Table II. Summarized data for all patients.

\begin{tabular}{|c|c|c|c|c|c|c|}
\hline Case & $\begin{array}{c}\text { Observation } \\
\text { period (months) }\end{array}$ & $\begin{array}{l}\text { Primary tumor } \\
\text { RR\% (MRI) }\end{array}$ & $\begin{array}{l}\text { Primary tumor } \\
\text { RR\% (US) }\end{array}$ & $\begin{array}{l}\text { Change in flow } \\
\text { signal }(C D-U S)^{c}\end{array}$ & $\begin{array}{l}\text { Change in PS } \\
\text { artifact (US) }\end{array}$ & $\begin{array}{c}\text { Change in } \\
\text { Ax-LN (CT) }\end{array}$ \\
\hline 1 & 25 & $\mathrm{CR}$ & CR & $\mathrm{P} \rightarrow \mathrm{N}$ & $\mathrm{N} \rightarrow \mathrm{P}$ & $\mathrm{P} \rightarrow \mathrm{N}$ \\
\hline 2 & 26 & $\mathrm{CR}$ & 72 & $\mathrm{P} \rightarrow \mathrm{N}$ & $\mathrm{N} \rightarrow \mathrm{P}$ & $\mathrm{P} \rightarrow \mathrm{N}$ \\
\hline 3 & 26 & CR & 30 & $\mathrm{P} \rightarrow \mathrm{N}$ & $\mathrm{N} \rightarrow \mathrm{N}$ & $\mathrm{P} \rightarrow \mathrm{N}$ \\
\hline 4 & 24 & CR & 77.4 & $\mathrm{P} \rightarrow \mathrm{N}$ & $\mathrm{N} \rightarrow \mathrm{P}$ & $\mathrm{P} \rightarrow \mathrm{P}^{\mathrm{f}}$ \\
\hline 5 & 24 & CR & CR & $\mathrm{P} \rightarrow \mathrm{N}$ & $\mathrm{N} \rightarrow \mathrm{N}$ & $\mathrm{P} \rightarrow \mathrm{N}$ \\
\hline 6 & 23 & CR & CR & $\mathrm{P} \rightarrow \mathrm{N}$ & $\mathrm{N} \rightarrow \mathrm{P}$ & $\mathrm{P} \rightarrow \mathrm{N}$ \\
\hline 7 & 16 & CR & 0 & $\mathrm{~N} \rightarrow \mathrm{N}$ & $\mathrm{N} \rightarrow \mathrm{P}$ & $\mathrm{P} \rightarrow \mathrm{N}$ \\
\hline 8 & 11 & $\mathrm{CR}$ & CR & $\mathrm{P} \rightarrow \mathrm{N}$ & $\mathrm{N} \rightarrow \mathrm{N}$ & $\mathrm{P} \rightarrow \mathrm{N}$ \\
\hline 9 & 13 & CR & CR & $\mathrm{P} \rightarrow \mathrm{N}$ & $\mathrm{N} \rightarrow \mathrm{N}$ & $\mathrm{P} \rightarrow \mathrm{N}$ \\
\hline 10 & 12 & CR & 47.4 & $\mathrm{P} \rightarrow \mathrm{N}$ & $\mathrm{N} \rightarrow \mathrm{N}$ & $\mathrm{P} \rightarrow \mathrm{N}$ \\
\hline 11 & 8 & $\mathrm{CR}$ & CR & $\mathrm{P} \rightarrow \mathrm{N}$ & $\mathrm{N} \rightarrow \mathrm{N}$ & $\mathrm{P} \rightarrow \mathrm{P}^{\mathrm{g}}$ \\
\hline 12 & 8 & $\mathrm{CR}$ & $\mathrm{CR}$ & $\mathrm{P} \rightarrow \mathrm{N}$ & $\mathrm{N} \rightarrow \mathrm{N}$ & $\mathrm{N} \rightarrow \mathrm{N}$ \\
\hline 13 & 3 & CR & CR & $\mathrm{P} \rightarrow \mathrm{N}$ & $\mathrm{N} \rightarrow \mathrm{N}$ & $\mathrm{P} \rightarrow \mathrm{N}$ \\
\hline 14 & 3 & CR & 32.5 & $\mathrm{P} \rightarrow \mathrm{N}$ & $\mathrm{P} \rightarrow \mathrm{P}$ & $\mathrm{P} \rightarrow \mathrm{N}$ \\
\hline 15 & 3 & CR & 78.8 & $\mathrm{P} \rightarrow \mathrm{N}$ & $\mathrm{N} \rightarrow \mathrm{P}$ & $\mathrm{P} \rightarrow \mathrm{N}$ \\
\hline 16 & 1 & $\mathrm{CR}$ & 59.1 & $\mathrm{P} \rightarrow \mathrm{N}$ & $\mathrm{N} \rightarrow \mathrm{N}$ & $\mathrm{P} \rightarrow \mathrm{N}$ \\
\hline 17 & 1 & CR & 63.6 & $\mathrm{P} \rightarrow \mathrm{N}$ & $\mathrm{P} \rightarrow \mathrm{P}$ & $\mathrm{P} \rightarrow \mathrm{N}$ \\
\hline
\end{tabular}

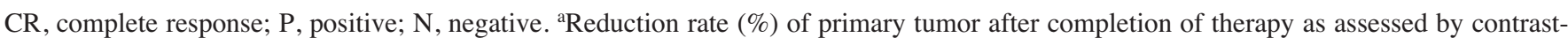
enhanced breast MRI. ${ }^{b}$ Reduction rate $(\%)$ of primary tumor after completion of therapy as assessed by ultrasonography. ${ }^{\mathrm{c}} \mathrm{Change}$ in flow signal on color Doppler ultrasonography after therapy compared to before therapy. ${ }^{\mathrm{d}}$ Change in posterior shadow artifact from primary tumor on ultrasonography after therapy compared to before therapy. ${ }^{\mathrm{e}}$ Change in axillary lymph node findings after therapy compared to before

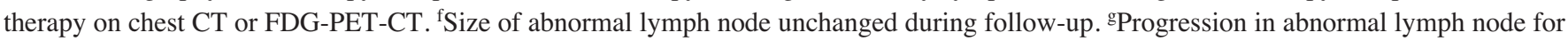
a woman who refused adjuvant chemotherapy.

time the patient had available, as the superiority of therapeutic effect remains unclear between these taxanes (12). Docetaxel was injected intravenously at $100 \mathrm{mg} / \mathrm{m}^{2}$ for $1 \mathrm{~h}$ every 3 weeks. Intravenous infusion of paclitaxel was repeated weekly in 3 of every 4 weeks. Trastuzumab was administered as a $4 \mathrm{mg} / \mathrm{kg}$ loading dose followed by $2 \mathrm{mg} / \mathrm{kg}$ weekly for 12 weeks, concurrent with adjuvant taxane chemotherapy for patients with HER2 overexpression, as determined by fluorescent in situ hybridization.

Endocrine therapy. All patients, if the breast tumor showed positive results for hormone receptor, received endocrine therapy just after completion of radiotherapy (Fig. 1). Tamoxifen (40 mg/day per os) and an aromatase inhibitor (anastrozole $1 \mathrm{mg} /$ day or exemestane $25 \mathrm{mg}$ /day per os) were used for pre- and post-menopausal patients, respectively. Endocrine therapy was planned to be continued for 5 years for all eligible patients.

Patient assessment (primary breast tumor and toxicity of therapy). Tumor response was assessed according to the Response Evaluation Criteria In Solid Tumors (13) using CE breast MRI and US. Patients were assigned to a toxicity grade from a standard assessment scale (National Institutes of Health common toxicity criteria). Treatment-related compli- cations were assessed in detail to evaluate the feasibility of this approach. Posterior shadow artifacts from tumor on US and flow signals on color Doppler US were also assessed. Each breast mass was scanned using a US unit (LOGIQ700 MR; GE Healthcare, Milwaukee, WI, USA) with a 7- to 11-MHz linear-array transducer. CE breast MRI was performed using a 3.0-T unit (Signa EXCITE HDx; GE Healthcare) with the subject in a prone position. Dynamic MRI using a 3-dimensional (3D) fast spoiled gradient-echo sequence (VIBRANT, volume imaging for breast imaging; repetition time, $7.0 \mathrm{~ms}$; echo time, $4.0 \mathrm{~ms}$; flip angle, $10^{\circ}$; field of view, $36 \times 36 \mathrm{~cm}$; matrix, 512x256; slice thickness, $3 \mathrm{~mm}$; space, $0 \mathrm{~mm}$; no. of excitations, 0.7$)$ was obtained before and 8 times (every $30 \mathrm{sec}$ ) after bolus injection of $0.1 \mathrm{mmol} / \mathrm{kg}$ gadolinium-diethylenetriamine pentaacetic acid at a rate of $3 \mathrm{ml} / \mathrm{sec}$. The interpreters of US (K.K.) and MRI (Y.M.) were provided with information regarding tumor location, but were blinded to undergoing therapy.

Patient assessment (axillary lymph node). The criterion for abnormal axillary lymph nodes was the existence of $\geq 1$ node $>5 \mathrm{~mm}$ in the short axis on chest CT or FDG-PET-CT $(14,15)$. Lymph nodes replaced at the center by fat were not considered to be pathological, even if size was $>5 \mathrm{~mm}$ in the short axis. Any focally elevated PET signal above normal 


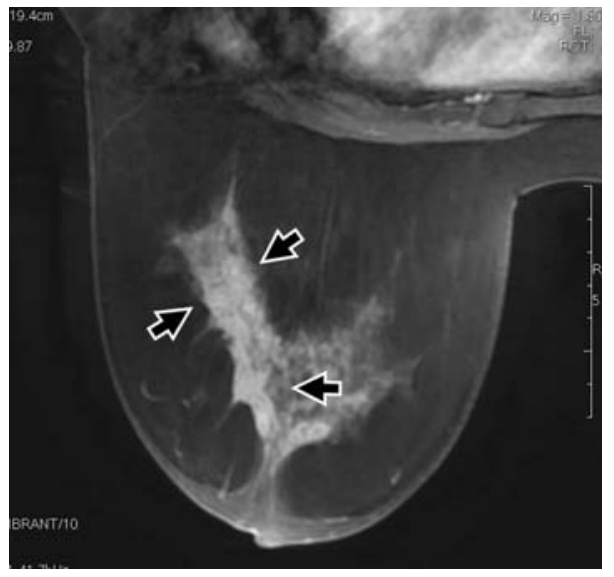

c

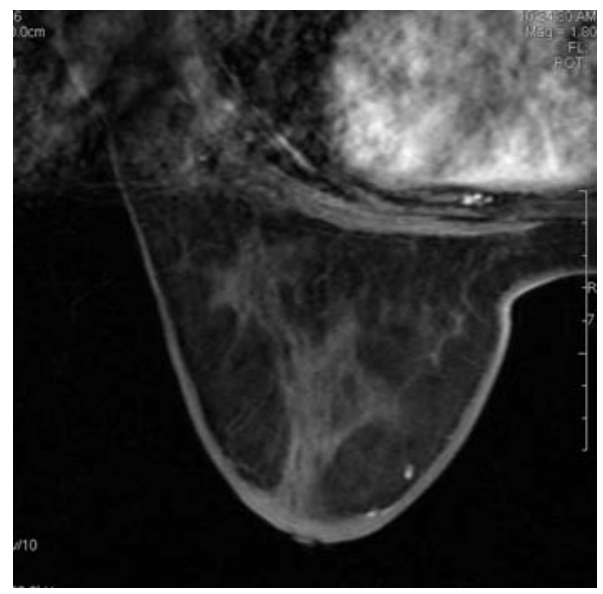

e

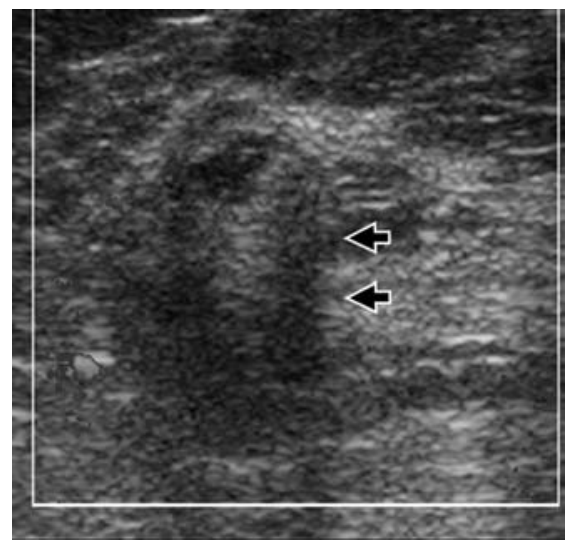

g

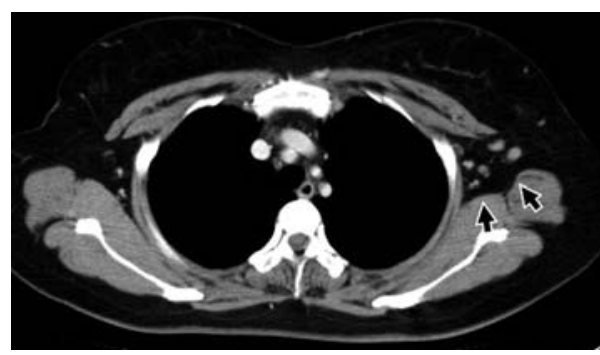

i

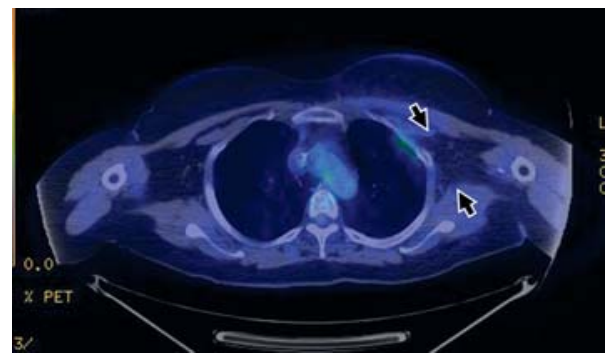

b

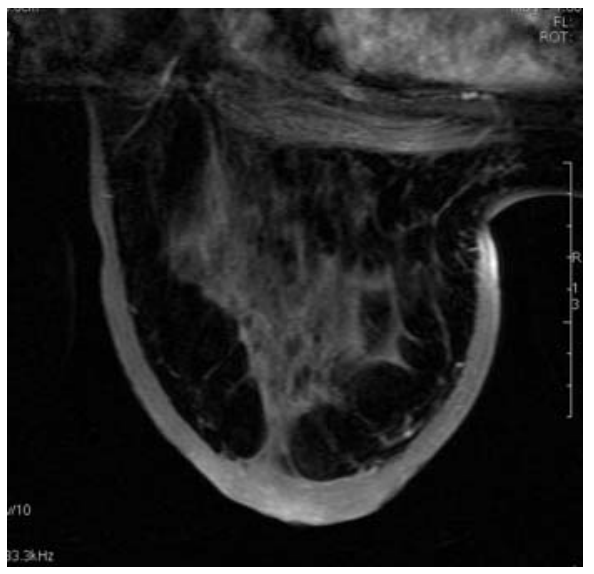

d

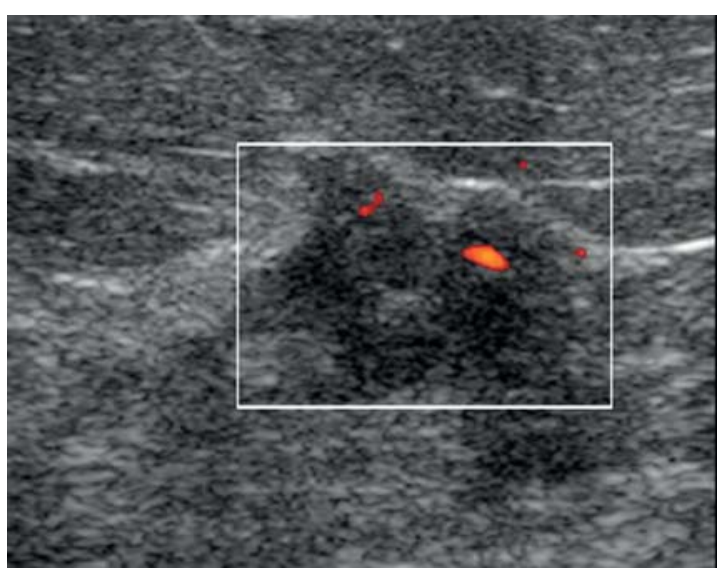

f

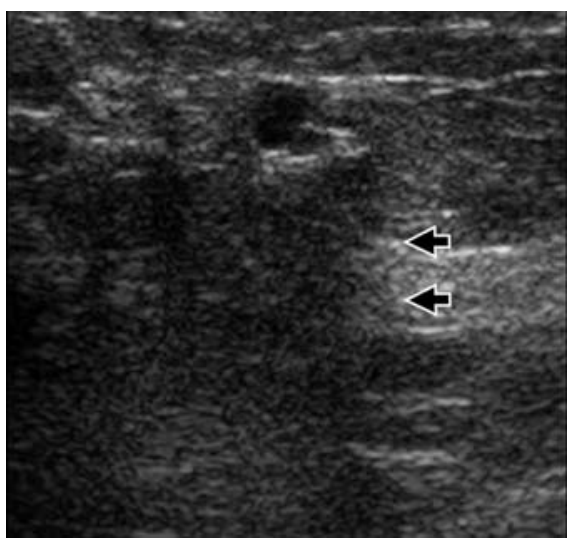

h

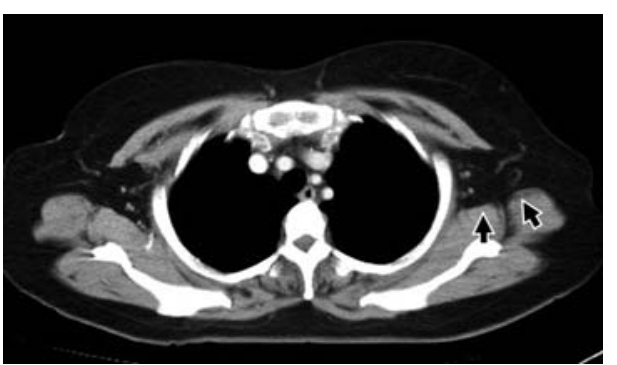

Figure 2. A 44-year-old woman with LABC (case 1 in Tables I and II). Initial CE breast MRI showed an enhanced large breast tumor (a) (arrows). Complete response was achieved just after therapy on CE breast MRI (b). No recurrence was identified on final CE breast MRI (c). Initial US depicted a low echoic breast tumor and intratumoral color flow signals (d). Complete response was achieved just after therapy (e) and on final follow-up US (f), while posterior shadow artifacts appeared just after therapy (e) and on final US study (f) (arrows). Initial chest CT showed positive results for left axillary lymph node metastases (g) (arrows). Left axillary lymph nodes were negative both just after therapy on chest CT (h) and on final FDG-PET-CT (i) (arrows). 
that could be mapped to a lymph node was also rated as a positive sign of metastasis (15). The interpreters of chest CT (N.H.) and FDG-PET-CT (K.M.) were provided with information about primary breast tumor, but were blinded to data on staging and therapy. Chest CT was performed using a 16-multidetector CT scanner (Aquilion; Toshiba Medical Systems, Tokyo, Japan) with the following parameters: thickness, $3 \mathrm{~mm}$; $120 \mathrm{kV}$, 60-70 mAs; 1-mm slice collimation; table speed, $46 \mathrm{~mm} / \mathrm{sec}$. Patients were scanned in a supine position $1 \mathrm{~min}$ after intravenous contrast agent injection at a flow rate of $2 \mathrm{ml} / \mathrm{sec}$. Whole-body FDG-PET-CT scans were obtained using a Discovery ST Elite PET-CT system (GE Healthcare), comprising a full-ring dedicated PET and a 16slice spiral CT. All patients were instructed to fast $6 \mathrm{~h}$ before receiving an intravenous application of $3.5 \mathrm{MBq} / \mathrm{kg}$ FDG. Imaging started $\sim 60 \mathrm{~min}$ after application of FDG. CT was acquired before PET with $50 \mathrm{~mA} / \mathrm{sec}$ at $130 \mathrm{kV}$ without administration of non-ionic contrast agent. All images were reconstructed with $5-\mathrm{mm}$ slice thickness and $3.7-\mathrm{mm}$ increment. After CT a 3D-mode PET was performed. PET emission time was adapted to the body weight of the patient: $<65 \mathrm{~kg}, 2 \mathrm{~min} /$ bed position; $65-85 \mathrm{~kg}, 2.5 \mathrm{~min} /$ bed position; and $>85 \mathrm{~kg}, 3 \mathrm{~min} /$ bed position

Beginning and frequency of observation. Both assessment of primary tumor and axillary nodes started within 2-4 weeks after the completion of adjuvant chemotherapy, regardless of endocrine therapy (Fig. 1). CE breast MRI, chest CT and FDG-PET-CT were performed at least once a year following the completion of chemotherapy. US and clinical examinations were performed every 3 months. Mean duration of observation was 13.4 months (range, 1-26 months).

\section{Results}

Adverse events. All patients experienced mild local pain at the injection site. For all 17 patients, radiation-induced dermatitis was mild (Grade I) and equivalent to that observed in our facility after radiotherapy alone, as described in our previous report (11). Chemotherapy did not result in adverse events severe enough to warrant withdrawal of therapy after appropriate supportive therapy was provided (i.e., anti-allergic agent, anti-emetic drugs). However, 1 patient (case 11 in Tables I and II), refused adjuvant chemotherapy based on a mistaken impression of chemotherapy, despite experiencing only mild adverse events.

Primary breast tumor (as assessed by CE breast MRI). Patient data are summarized in Tables I and II. All patients achieved complete response (CR) after being unable or unwilling to undergo surgery and therefore undertaking non-surgical breast-conservation therapy (Figs. 2 and 3). These patients have so far shown no local recurrence.

Primary breast tumor (as assessed by US). Patient data are summarized in Tables I and II. US depicted tumor-like findings in 9 of the 17 patients (Fig. 3) (CR, 8 cases; partial response (PR), 8 cases; stable disease (SD), 1 case). The size of the tumor-like finding changed little during the observation period (Fig. 3). A posterior shadow artifact appeared frequently after therapy (8/17) compared to baseline data (2/17) (Figs. 2 and 3). The frequency of posterior shadows remained unchanged during the observation period. Color Doppler US depicted intratumoral flow signals in 16 of 17 tumors before therapy, but these flow signals disappeared from all patients after completion of therapy (Figs. 2 and 3). Absence of flow signals continued throughout the observation period.

Axillary lymph nodes (as assessed by chest CT or FDG-PETCT). Data on axillary nodes are shown in Table II. Chest CT depicted lymph node abnormalities in 16 of 17 patients before therapy (Figs. 2 and 3). Lymph nodes became normal in all except 2 patients after completion of therapy (Figs. 2 and 3). Abnormal lymph nodes remained stable in 1 patient (case 4 in Table II), but deteriorated in another patient (case 11 in Table II). The progression in abnormal lymph nodes was seen in the woman who refused adjuvant chemotherapy.

\section{Discussion}

Surgery alone cannot control LABC, and the 5-year survival rate is poor, at $<20 \%$ (5). Fisher established the concept in the 1970 s and 1980 s that breast cancer is a systemic disease, needing systemic therapy for management (16). Induction chemotherapy followed by locoregional therapy is recommended for the management of LABC $(2-4,17)$. Surgery alone and radiotherapy alone following induction chemotherapy have achieved equivalent survival rates in LABC patients $(5,6)$. Axillary dissection alone showed a higher 5year survival rate compared to radiotherapy alone following breast-conserving surgery for early-stage breast cancer in a report from the Curie laboratory (18). However, the use of adjuvant chemotherapy for node metastasis-positive cases in the axillary dissection group but not in the radiotherapy group appears likely to have biased that result (18). A subsequent report from the same laboratory showed equivalent 15 -year survival rates between axillary dissection alone and radiotherapy alone (19). No results have indicated that surgical results surpass those of radiotherapy in the management of large breast cancer and axillary node metastases in terms of survival rate $(5,6,18,19)$. However, surgery surpasses radiotherapy in the locoregional management of breast cancer $(5,6,18,19)$. Our new treatment, using radiotherapy assisted by a new radiosensitizer combined with systemic chemotherapy and endocrine therapy, yielded excellent locoregional management in this initial assessment. Such results suggest a strong potential to remove surgery from the therapeutic options for LABC, as radiotherapy originally appeared equivalent to surgery in terms of survival after LABC, and has now obtained advances in locoregional management. However, further investigation with long-term follow-up and a large study population are needed to confirm the reliability of the present findings.

Currently, most radiotherapy for breast cancer is performed using X-rays or high-energy electron beams from a linear accelerator $(2-6,20,21)$, but these forms of low-linear energy transfer (LET) radiation are not ideal for radiotherapy compared to high-LET radiation. To overcome the dis- 


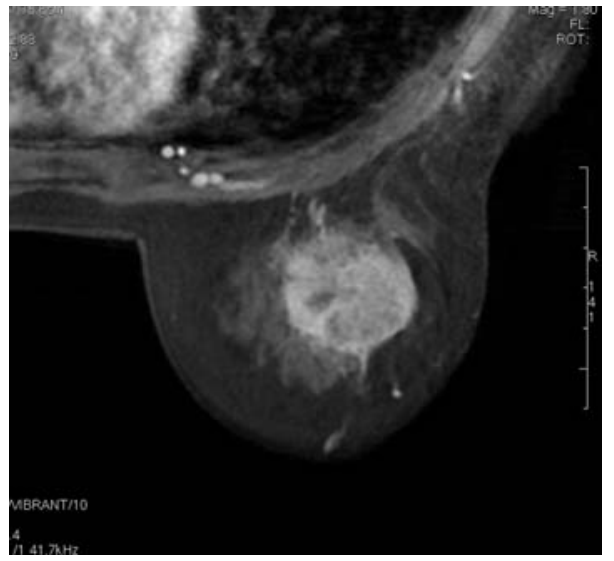

c

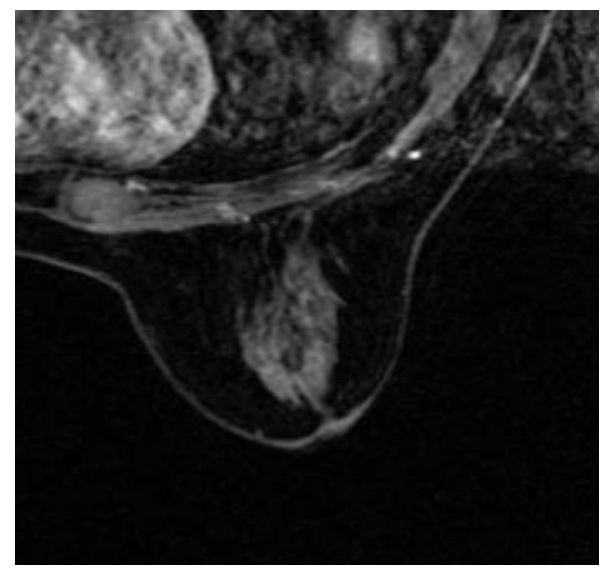

e

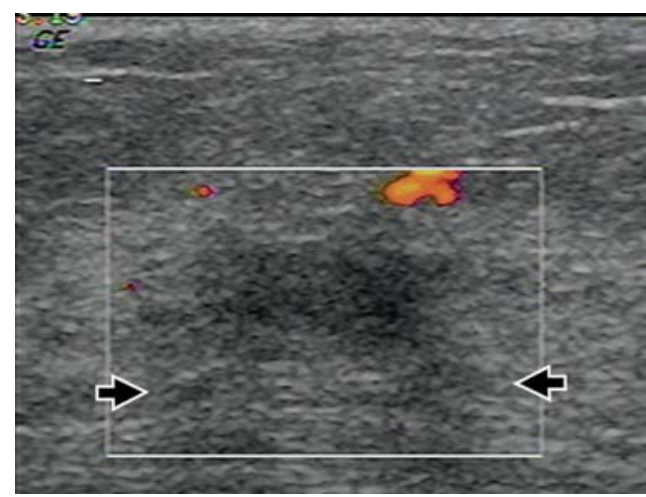

g

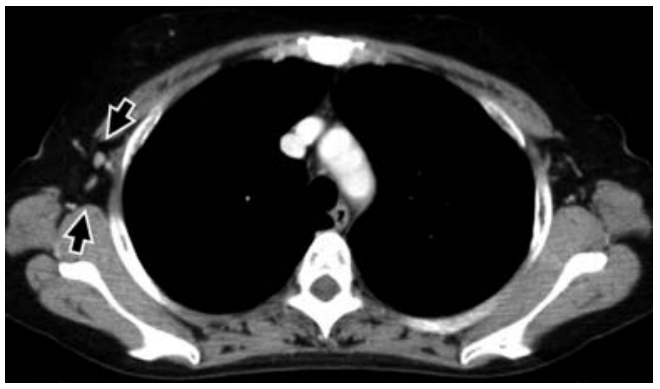

i

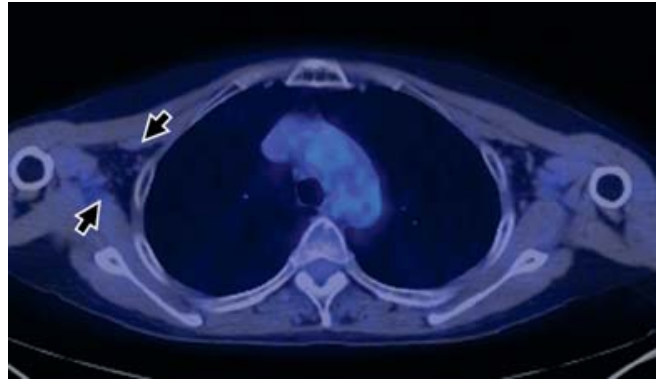

b

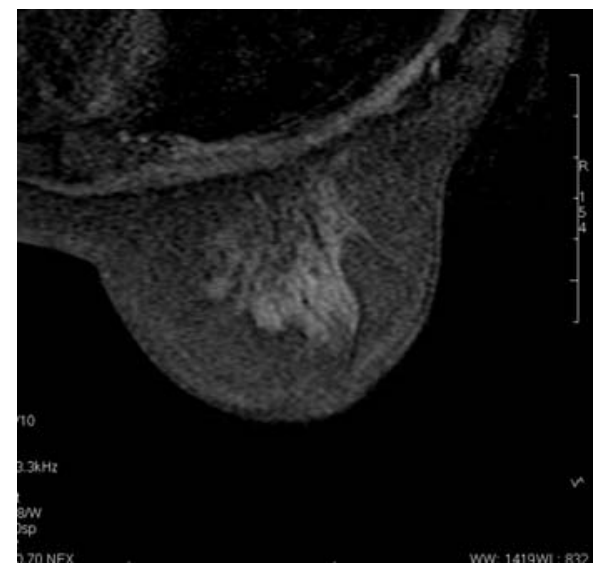

d

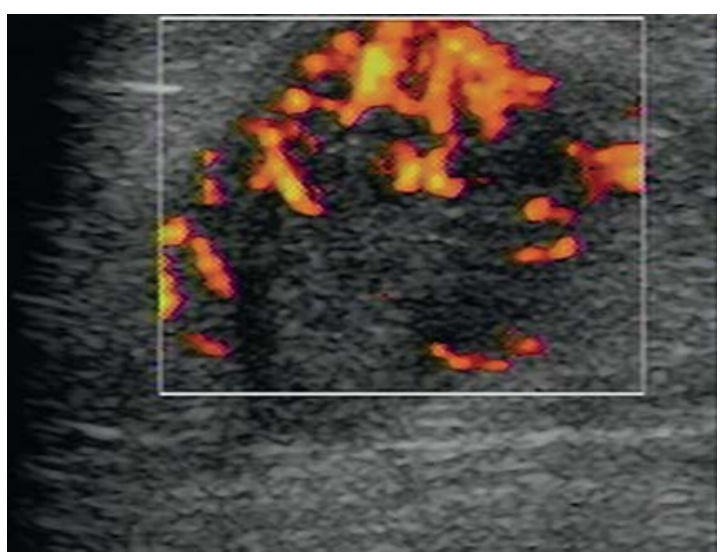

f

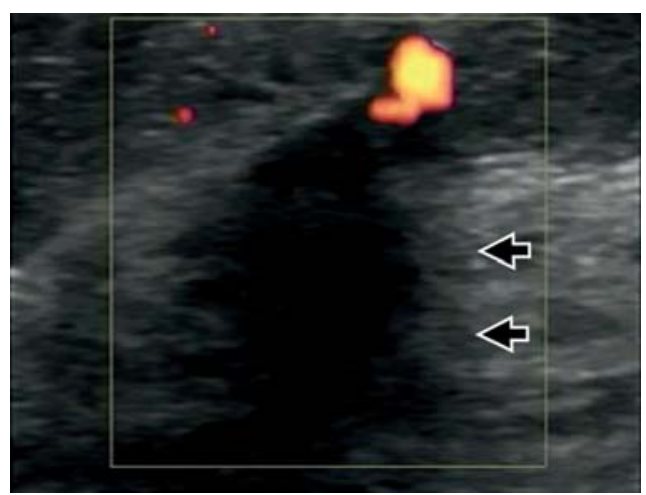

h

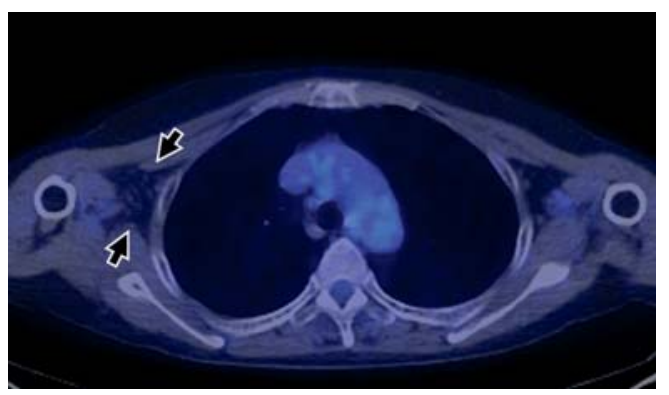

Figure 3. A 60-year-old woman with LABC (case 2 in Tables I and II). Initial CE breast MRI showed an enhanced large breast tumor (a). Complete response was achieved just after therapy on CE breast MRI (b). No recurrence was evident on final CE-breast MRI (c). Initial US depicted a low echoic breast tumor and intratumoral color flow signal (d). US depicted tumor-like findings just after therapy (e) and at final follow-up (f). Posterior shadow artifacts appeared just after therapy (e) and became more evident at the final US study (f) (arrows). Color flow signals disappeared from the tumor-like finding after therapy (e and f). Initial chest CT showed positive findings for right axillary lymph node metastases (g) (arrows). Right axillary lymph nodes appeared negative both just after therapy (h) and at final FDG-PET-CT (i) (arrows). 
advantage of these low-LET beams, we introduced a new radiosensitizer containing hydrogen peroxide and sodium hyaluronate for intra-tumoral injection. Theoretically, this inactivates anti-oxidative enzymes and produces oxygen in topical tumor tissue, and appears able to convert radioresistant tumors into radiosensitive ones. We have already reported favorable efficacy of this new radiosensitizer in vivo and in some preliminary clinical trials (7-11). Although several studies in the late 1960s and early 1970s investigated the use of hydrogen peroxide in radiotherapy, this line of investigation appears to have been discontinued $(22,23)$. We combined sodium hyaluronate with hydrogen peroxide to preserve oxygen concentrations in tumor tissue for $>24 \mathrm{~h}$, while intratumoral injection of hydrogen peroxide alone results in a rapid lowering of oxygen concentrations (unpublished data). This might be one factor needed to enable the use of hydrogen peroxide as a radiosensitizer.

Furthermore, global advances in systemic therapy for breast cancer appear likely to enhance our treatment. Systemic chemotherapy has become the standard of care for women with LABC (2-4,17). Several studies have indicated correlations between chemotherapy response and survival $(24,25)$. These data led to the hypothesis that locoregional response to neoadjuvant chemotherapy could be used as a surrogate for the overall systemic efficacy of chemotherapy. In addition, early identification of drug resistance can promote a change to potentially more effective regimens (25). Following these hypotheses, we could exchange an EC regimen with a taxane regimen if the tumor does not respond to EC. Recently, taxanes have been widely viewed as beneficial and are increasingly used for patients with node-positive breast cancer (12). We consider that adjuvant trastuzumab is recommendable for patients with HER2-positive LABC in view of the demonstrated benefit of adding this agent to adjuvant chemotherapy in early-stage disease (26). Adjuvant endocrine therapies, such as tamoxifen and aromatase inhibitors, also increase the survival rate and represent an acceptable option for patients with hormone receptor-positive LABC (27). These advances in systemic care for breast cancer support our clinical results.

Precise assessment of therapeutic efficacy is also central to the success of our clinical trial. CE breast MRI offers $>95 \%$ sensitivity to breast cancer with enhancement of the lesion by gadolinium-based contrast material $(28,29)$. CE breast MRI can accurately reveal the extent of tumor spread regardless of prior neoadjuvant chemotherapy (30-32). US is reportedly more reliable than mammography for detecting and measuring the size of breast tumors, particularly in cases of dense breast (33-35). Both chest CT and FDG-PET-CT are reliable modalities to monitor the staging of lymph nodes $(14,15)$. We therefore employed MRI and US as diagnostic tools for primary breast tumor. Conversely, we used chest CT and FDG-PET-CT to assess nodal staging. In the current report, US depicted tumor-like findings in some cases defined as CR on CE breast MRI. Compared to US, CE breast MRI provides equivalent to superior detection rates for bulky breast masses (35-37). Moreover, CE breast MRI shows higher sensitivity to small lesions, such as intraductal spread, compared to US $(36,37)$. These tumor-like findings on US after therapy thus seem likely to represent scar tissue. Fibrous scar tissue that develops after exposure to radiation $(38,39)$ would cause ultrasound attenuation (40) as the source of the posterior shadow artifact. The higher rate of posterior shadow artifacts on US and the absence of flow signals on color Doppler US after therapy support the likelihood that the tumor-like finding represents scar tissue (41). The current results suggest that tumor-like findings after therapy on US do not necessarily indicate tumor recurrence. CR on CE breast MRI thus represents a reliable indicator of our treatment efficacy.

In conclusion, KORTUC II combined with systemic therapy has strong potential to obviate surgery as a therapeutic option for LABC based on our locoregional therapeutic outcomes. Radiological imaging modalities including CE breast MRI, US, chest CT and FDG-PET-CT allow monitoring of the therapeutic effect and are necessary for the success of this therapy. Further investigations are needed to confirm the long-term therapeutic outcomes using this new approach to LABC.

\section{References}

1. UICC: TNM Classification of Malignant Tumors. 6th edition. Wiley-Liss, New York, 2002.

2. Rouzier R, Extra JM, Carton M, et al: Primary chemotherapy for operable breast cancer: incidence and prognostic significance of ipsilateral breast tumor recurrence after breast-conserving surgery. J Clin Oncol 19: 3828-3835, 2001.

3. Lerouge D, Touboul E, Lefranc JP, Genestie C, MoureauZabotto L and Blondon J: Locally advanced non-inflammatory breast cancer treated by combined chemotherapy and preoperative irradiation: updated results in a series of 120 patients. Cancer Radiother 8: 155-167, 2004.

4. Low JA, Berman AW, Steinberg SM, Danforth DN, Lippman ME and Swain SM: Long-term follow-up for locally advanced and inflammatory breast cancer patients treated with multimodality therapy. J Clin Oncol 22: 4067-4074, 2004.

5. Perloff M, Lesnick GJ, Korzun A, et al: Combination chemotherapy with mastectomy or radiotherapy for stage III breast carcinoma: a Cancer and Leukemia Group B study. J Clin Oncol 6: 261-269, 1988

6. De Lena M, Varini M, Zucali R, et al: Multimodal treatment for locally advanced breast cancer. Result of chemotherapyradiotherapy versus chemotherapy-surgery. Cancer Clin Trials 4: 229-236, 1981.

7. Ogawa Y, Takahashi T, Kobayashi T, et al: Mechanism of apoptotic resistance of human osteosarcoma cell line, HS-Os-1, against irradiation. Int J Mol Med 12: 453-458, 2003.

8. Ogawa Y, Takahashi T, Kobayashi T, et al: Apoptoticresistance of the human osteosarcoma cell line HS-Os-1 to irradiation is converted to apoptotic-susceptibility by hydrogen peroxide: a potent role of hydrogen peroxide as a new radiosensitizer. Int J Mol Med 12: 845-850, 2003.

9. Ogawa Y, Takahashi T, Kobayashi T, et al: Immunocytochemical characteristics of human osteosarcoma cell line HS-Os-1: possible implication in apoptotic resistance against irradiation. Int J Mol Med 14: 397-403, 2004

10. Ogawa Y, Ue H, Tsuzuki K, et al: New radiosensitization treatment (KORTUC I) using hydrogen peroxide solutionsoaked gauze bolus for unresectable and superficially exposed neoplasms. Oncol Rep 19: 1389-1394, 2008.

11. Ogawa Y, Kubota K, Ue H, et al: Phase I study of a new radiosensitizer containing hydrogen peroxide and sodium hyaluronate for topical tumor injection: a new enzyme-targeting radiosensitization treatment, Kochi Oxydol-Radiation Therapy for Unresectable Carcinomas, Type II (KORTUC II). Int J Oncol 34: 609-618, 2009.

12. Sparano JA, Wang M, Martino S, et al: Weekly paclitaxel in the adjuvant treatment of breast cancer. N Engl J Med 358: 1663-1671, 2008.

13. Therasse P, Arbuck SG, Eisenhauer EA, et al: New guidelines to evaluate the response to treatment in solid tumors. European Organization for Research and Treatment of Cancer, National Cancer Institute of the United States, National Cancer Institute of Canada. J Natl Cancer Inst 92: 205-216, 2000. 
14. Hata Y, Ogawa Y, Nishioka A, Inomata T and Yoshida S: Thin section computed tomography in the prone position for detection of axillary lymph node metastases in breast cancer. Oncol Rep 5: 1403-1406, 1998.

15. Heusner TA, Kuemmel S, Hahn S, et al: Diagnostic value of fulldose FDG PET/CT for axillary lymph node staging in breast cancer patients. Eur J Nucl Med Mol Imaging 36: 1543-1550, 2009.

16. Fisher B, Redmond C and Fisher ER: The contribution of recent NSABP clinical trials of primary breast cancer therapy to an understanding of tumor biology - an overview of findings. Cancer 46: 1009-1025, 1980.

17. Kaufmann M, Hortobagyi GN, Goldhirsch A, et al: Recommendations from an international expert panel on the use of neoadjuvant (primary) systemic treatment of operable breast cancer: an update. J Clin Oncol 24: 1940-1949, 2006.

18. Cabanes PA, Salmon RJ, Vilcoq JR, et al: Value of axillary dissection in addition to lumpectomy and radiotherapy in early breast cancer. Lancet 339: 1245-1248, 1992.

19. Louis-Sylvestre C, Clough K, Asselain B, et al: Axillary treatment in conservative management of operable breast cancer: dissection or radiotherapy? Results of a randomized study with 15 years of follow-up. J Clin Oncol 22: 97-101, 2004.

20. Ogawa $\mathrm{Y}$, Nishioka $\mathrm{A}$, Inomata $\mathrm{T}$, et al: Conservation treatment intensified with an anti-estrogen agent and CAF chemotherapy for stage I and II breast cancer. Oncol Rep 7: 479-484, 2000 .

21. Ogawa Y, Nishioka A, Inomata T, et al: Conservation treatment intensified with tamoxifen and CAF chemotherapy without axillary dissection for early breast cancer patients with clinicallynegative axillary nodes. Oncol Rep 6: 801-805, 1999.

22. Chasin WD, Gross CC, Wang CC and Miller D: Hydrogen peroxide and irradiation of tumors. Arch Otolaryngol 85: 151-155, 1967.

23. Bianchini G, Salgarello G, Mennini T and Lorini G: Intraarterial infusion of hydrogen peroxide in radiotherapy of malignant tumors. Radiol Med 55: 207-225, 1969.

24. Bonadonna G, Valagussa P, Brambilla C, Ferrari L, Moliterni A, Terenziani $\mathrm{M}$ and Zambetti M: Primary chemotherapy in operable breast cancer: eight-year experience at the Milan Cancer Institute. J Clin Oncol 16: 93-100, 1998.

25. Thomas E, Holmes FA, Smith TL, et al: The use of alternate, non-cross-resistant adjuvant chemotherapy on the basis of pathologic response to a neoadjuvant doxorubicin-based regimen in women with operable breast cancer: long-term results from a prospective randomized trial. J Clin Oncol 22: 2294-2302, 2004.

26. Joensuu H, Kellokumpu-Lehtinen PL, Bono P, et al: Adjuvant docetaxel or vinorelbine with or without trastuzumab for breast cancer. N Engl J Med 354: 809-820, 2006.

27. Coates AS, Keshaviah A, Thurlimann B, et al: Five years of letrozole compared with tamoxifen as initial adjuvant therapy for postmenopausal women with endocrine-responsive early breast cancer: update of study BIG 1-98. J Clin Oncol 25: 486-492, 2007.

28. Esserman L, Hylton N, George T and Weidner N: Contrastenhanced magnetic resonance imaging to assess tumor histopathology and angiogenesis in breast carcinoma. Breast J 5: 13-21, 1999
29. Esserman L, Hylton N, Yassa L, Barclay J, Frankel S and Sickles E: Utility of magnetic resonance imaging in the management of breast cancer: evidence for improved preoperative staging. J Clin Oncol 17: 110-119, 1999

30. Tsuboi N, Ogawa Y, Inomata T, Yoshida D, Yoshida S, Moriki T and Kumon M: Changes in the findings of dynamic MRI by preoperative CAF chemotherapy for patients with breast cancer of stage II and III: pathologic correlation. Oncol Rep 6: 727-732, 1999.

31. Kubota K, Ogawa Y, Nishioka A, et al: Diagnostic accuracy of mammography, ultrasonography and magnetic resonance imaging in the detection of intraductal spread of breast cancer following neoadjuvant chemotherapy. Oncol Rep 17: 915-918, 2007.

32. Nakamura S, Kenjo H, Nishi T, Kazama T, Doi O and Suzuki K: Efficacy of 3D-MR mammography for breast conserving surgery after neoadjuvant chemotherapy. Breast Cancer 9: 15-19, 2002.

33. Leconte I, Feger C, Galant C, Berliere M, Berg BV, D'Hoore W and Maldague B: Mammography and subsequent whole-breast sonography of non-palpable breast cancers: the importance of radiologic breast density. AJR 180: 1675-1679, 2003.

34. Yang WT, Lam WW, Cheung H, Suen M, King WW and Metreweli C: Sonographic, magnetic resonance imaging, and mammographic assessments of preoperative size of breast cancer. J Ultrasound Med 16: 791-797, 1997.

35. Berg WA, Gutierrez L, NessAiver MS, Carter WB, Bhargavan M, Lewis RS and Ioffe OB: Diagnostic accuracy of mammography, clinical examination, US, and MR imaging in preoperative assessment of breast cancer. Radiology 233: 830-849, 2004.

36. Hata T, Takahashi H, Watanabe K, Takahashi M, Taguchi K, Itoh $\mathrm{T}$ and Todo $\mathrm{S}$ : Magnetic resonance imaging for preoperative evaluation of breast cancer: a comparative study with mammography and ultrasonography. J Am Coll Surg 198: 190-197, 2004.

37. Van Goethem M, Schelfout K, Dijckmans L, et al: MR mammography in the pre-operative staging of breast cancer in patients with dense breast tissue: comparison with mammography and ultrasound. Eur Radiol 14: 809-816, 2004.

38. Gottlober P, Kerscher MJ, Korting HC and Peter RU: Sonographic determination of cutaneous and subcutaneous fibrosis after accidental exposure to ionising radiation in the course of the Chernobyl nuclear power plant accident. Ultrasound Med Biol 23: 9-13, 1997.

39. Adams MJ, Lipshultz SE, Schwartz C, Fajardo LF, Coen V and Constine LS: Radiation-associated cardiovascular disease: manifestations and management. Semin Radiat Oncol 13: 346-356, 2003.

40. Jones JP and Leeman S: Ultrasonic tissue characterization. Acta Electronica 26: 3-31, 1984.

41. Baz E, Madjar H, Reuss C, Vetter M, Hackeloer B and Holz K: The role of enhanced Doppler ultrasound in differentiation of benign vs. malignant scar lesion after breast surgery for malignancy. Ultrasound Obstet Gynecol 15: 377-382, 2000. 